This document must be cited according to its final version which is published in a journal as:

$$
\text { P. Dufour }{ }^{1} \text {, }
$$

"Control Engineering in Drying Technology: Review and Trends", special issue of Drying Technology

on Progress in Drying technologies (5),

ISSN(printed): 0737-3937. ISSN (electronic): 1532-2300 24(7), pp. 889 - 904, 2006.

http://dx.doi.org/10.1080/07373930600734075

All open archive documents of Pascal Dufour are available at: http://hal.archives-ouvertes.fr/DUFOUR-PASCAL-C-3926-2008

The professional web page ( $\mathrm{Fr} / \mathrm{En}$ ) of Pascal Dufour is:

http://www.lagep.univ-lyon1.fr/signatures/dufour.pascal

1

Université de Lyon, Lyon, F-69003, France; Université Lyon 1;

CNRS UMR 5007 LAGEP (Laboratoire d'Automatique et de GEnie des Procédés),

43 bd du 11 novembre, 69100 Villeurbanne, France

Tel +33 (0) 472431845 - Fax +33 (0) 472431699

http://www-lagep.univ-lyon1.fr/ http://www.univ-lyon1.fr http://www.cnrs.fr 


\title{
Control Engineering in Drying Technology: Review and Trends
}

\author{
Dufour P. \\ LAGEP UMR CNRS 5007 \\ Université Claude Bernard Lyon 1 \\ 43 bd du 11 Novembre 1918 \\ 69622 Villeurbanne Cedex, France \\ dufour@lagep.univ-lyon1.fr
}

Key words: controller; control strategy; costs; energy.

\begin{abstract}
This paper aims at promoting cooperation between drying and control communities in the future. Indeed, with a review of 71 relevant publications all dealing with control aspects in drying, this paper shows that the use of control tools really started to emerge in drying applications only since 1979. In a second phase started around 1998, new trends based on more advanced concepts have also appeared in drying control. This paper clearly shows that control in drying is more and more a reality and that many opportunities exist to enhance industrial performance via efficient control of the operation.
\end{abstract}




\section{INTRODUCTION}

On one side, drying technology is a major energy consumer used in many industries including: agriculture, biotechnology, food, textile, mineral, pharmaceutical, pulp and paper, polymer, wood and others. It is also perhaps the oldest chemical engineering unit operation. Drying aims at reducing the moisture content within a product by application of thermal energy to produce dried products of desired attributes. Control of dryers was mainly manual in the early days; automatic control appeared only more recently in industrial drying equipment, especially with the introduction of PID control (the first paradigm in control) in 1942 by Ziegler and Nichols. Whereas control techniques have been widely used since the middle of the 1970's in the chemical industry, the number of applications of control in drying is still relatively modest. Indeed, with 60000 products dried and 100 dryer types commonly used worldwide ${ }^{[1,2]}$, and with the complexities of transport phenomena involved in drying, no single controller can be applied to all dryers. Moreover, most of the research is still focused on the understanding of the drying mechanisms and product quality rather than on control of the operation itself. Therefore, it is not surprising to see that relatively few published works deal with control aspects in drying. In the meantime, one has to note that the major cost of dryers is not in the initial investment (design and assembly) but in the daily operation, where control is very important to save energy and obtain desired product quality. It is therefore clear that dryer control is very important and that with deeper understanding of the drying, new "smart" dryers can be made more reliable and more cost-effective than classical dryers ${ }^{[1]}$.

This paper is organized as follows: first, some motivations for the use of control tools in drying are given, including the financial benefits. In the second part, some basic concepts of control engineering tools needed for this paper are reviewed briefly. Then, the main 
contribution of this paper deals with an evaluative analysis of 71 publications dealing with both drying and control. It attempts to show how control tools can be used in industrial drying and reviews the recent trends in dryer control, especially in terms of advanced control techniques and modelling.

\section{MOTIVATION FOR USE OF CONTROL IN INDUSTRIAL DRYING}

\section{Various formulations of the control problem}

During drying, the most important objective is to adjust some of the drying conditions ${ }^{[3]}$ while achieving the main final overall performances required.

- Increase the yield while obtaining the specified final properties and desired quality of the dried products needed for their commercial use. This includes: size, colour, visual appeal, porosity, stability, texture, stress resistance, etc. ${ }^{[4]}$. Moreover, one has to minimize the amount of off spec products induced by changes in some of the drying conditions: desired set-points (e.g.: a grade transition), velocities, feed rates, feed characteristics or atmospheric conditions (e.g.: the ambient mean humidity).

- Decrease the cost of production due to: the energy consumption, the maintenance cost and the drying time. Concerning the energy consumption, drying is a highly energyintensive operation and it represents from $10 \%$ to $25 \%$ of the national industrial energy in the developed world ${ }^{[1]}$. Moreover, it is also known that a majority of industrial dryers operate at low energy efficiency, from a disappointing $10 \%$ to a respectable $60 \%$ (this ratio is defined as the theoretical energy required for the drying to the actual energy 
consumed). Therefore, due to the escalating energy costs and more intensive global competition, these performances have to be improved. This can be done using control tools.

However, in many situations, the specified objectives are in conflict. For example, improved properties and quality often demand to increase the cost of production whereas decreasing the drying time may lead to decrease the quality. Therefore, adjusting the drying conditions is not straightforward and the objectives are often relaxed to obtain manual drying control procedures. Such manual control procedures are the easiest to obtain but the drawback is that overall performances are not the best one could expect. So, it is not a surprise that the development of a "smart dryer" has recently emerged in drying technology. In the "smart dryer", a controller automatically tunes the drying conditions such that the expected final overall performances are reached. Such a "smart" attitude is quiet common in others industry (e.g.: chemical industry) since a few decades and in comparison, relatively few works have been done until now in control in drying technology.

\section{Some benefits of control tools in drying technology}

We start with a review of several studies where the benefits obtained in the drying industry with the use of control tools are explicitly stated:

- For a grain dryer, an optimization procedure allowed to significantly decrease the drying cost by $33.6 \%$ from $2.29 £ / t$ to $1.52 £ / t$, with the optimal tuning of the airflows $30 \%$ less than "normal" [5]. The optimal tuning for the heater power became $85 \%$ less than "normal", [6]. 
- For a grain dryer, the use of an on-line optimal controller led to an $18 \%$ decrease in drying time, a $6.4 \%$ decrease in fuel consumption and a total cost decrease of $1.3 \%{ }^{[7]}$.

- In a beet sugar factory, the use of a model based predictive controller ${ }^{[8,9,10]}$ reduced the energy costs by $1.2 \%(18,900 £ /$ year $)$ and decreased the downstream energy cost by $14,000 £ /$ year. The product yield increased by $0.86 \%$ worth $61,600 £ /$ year and offspecification production has decreased from $11 \%$ to $4 \%$. Finally, the payback time (including hardware and development) was 17 months.

- For a rotary dryer, a PI controller was used to control the outlet mean product moisture content near the desired set-point ${ }^{[11]}$. The throughput was increased by $1.4 \%$ leading to a potential increase of a company profit by 105845 US\$/year. Concerning energy consumption, it decreased by $7 \%$ from $22069 \mathrm{~kW}$ (manual control) to $20483 \mathrm{~kW}$ (automatic control). Based on an 80000 US\$ control system, the payback time (including hardware and development) was 9 months.

Clearly, one can see that the use of control tools allows to improve benefits, and to decrease energy consumption and off-specification production. Moreover, even if the initial control study is not simple (e.g.: in case of both first principle model and software developments), the return on this investment is relatively short as it does not exceed 1.5 years. 


\section{BASIS FOR CONTROL}

In this part, some concepts of control engineering are reviewed in the context of the aim and scope of this paper.

\section{Design variables vs. manipulated control}

Basically, the drying procedure depends on two families of variables:

- Design variables such as the dryer type, actuators, sensors, equipments and dimensions. Such variables appear when the dryer does not exist. The choice and the value of such variables are the first to be discussed in order to design and build the dryer.

- Manipulated variables (or decision variables or control actions) such that heating power, air flow rate and air humidity. After the design and the building of the dryer, the value of such variables has to be tuned off-line (before the drying) or on-line (during the drying) either manually or automatically.

In terms of control engineering, tuning of both design variables and manipulated variables needs to be discussed. But, due to lack of a multidisciplinary approach, usually control engineers are not involved in the decisions concerned with the design variables, even if these variables also have a large impact on the performance of the drying operation. For example, the type, location and number of sensors, that are very important for on-line control, are usually not considered seriously for this purpose during the process design stage. In this 
paper, our discussion deals only with the tuning of the manipulated variables, which is the fundamental issue in control.

\section{Objectives for the tuning of the manipulated variables}

The need for the tuning of the manipulated variables is a direct consequence of the original control problem, which is classically one of the following two problems:

- In a regulation problem, a constant set-point vector is defined (e.g.: the desired final mean moisture contents). The problem is to choose and design a controller that tunes the manipulated variables, such that the considered controlled variables (e.g.: final mean moisture contents of the product) tracks as best as possible their respective set-point and with a minimum variability during the drying.

- In an optimization problem, the idea is initially to state the criteria accounting for the controlled variables and/or the manipulated variables and/or the available state variables (which contain all the dynamic characteristics of the drying). Then, an optimization procedure adjusts the manipulated variables as to minimize these criteria. Constraints dealing with process limitations (e.g.: actuators magnitude have upper and lower bounds), process safety (e.g.: a maximum temperature threshold beyond which operation becomes hazardous), process specification (e.g.: a maximum known surface temperature beyond which final quality is too altered) may be explicitly incorporated into this formulation. 
Finally, controller performances may be compared according to a combination of the following objectives:

- Decrease the rise time, defined as $10 \%$ to $90 \%$ of the time needed by a controlled variable to move from the initial constant value to a new constant value (e.g.: after a change in set-points).

- Decrease the overshoots that may occur if the controlled variable has an unstable behaviour.

- Decrease the steady-state error, which is the error between the set-point and the controlled variable when the dynamic behaviour has disappeared.

- Improve the disturbances rejection: a good controller is requested to rapidly attenuate the effects of the disturbances over the controlled variables (e.g.: without control, a change in atmospheric humidity affects the final moisture content of a product).

- Improve the robustness: a good controller is requested to be able to account for a large variety of similar products, even if some uncontrolled drying conditions or feed characteristics change (e.g.: the initial moisture content of a product).

\section{Off-line control (open loop) vs. on-line control (closed loop)}

Manipulated variables can be tuned in two ways: 
- Off-line control (open loop control): if the drying behaviour, the desired product specifications, the uncontrolled operating conditions and the feed characteristics are known in advance accurately, an easy way to control a dryer is to tune (by computation or manually) the manipulated variables before the beginning of the drying. These values are then used during the drying.

- On-line control (closed loop control): in reality, desired product specifications are most of the time known in advance, but atmospheric operating conditions and feed characteristics may be time-varying, may not be measured and they usually strongly influence the drying. An efficient way to control a dryer is then to tune (automatically or manually) the manipulated variables during the drying in order to obtain the best control results using the time varying measures available.

In this paper, although both approaches are discussed, the focus is on the on-line control, which is a more powerful tool in control engineering. Indeed, the measures made during the drying are used to adjust the manipulated variables. This is very helpful to improve the drying performances. If they are measured, time varying drying conditions may also be accounted for. Unfortunately, until now, off-line control approaches are more often used in drying engineering than the on-line control approaches. This is partially due to a lack of knowledge of drying engineers in the control tools and especially the benefits that can be obtained with their implementation. We hope that this paper will help to bring closer these two groups of experts. Moreover, due to lack of accurate and reliable sensors available for such a wide range of products, it is also difficult to get the on-line measures needed by the controller. This made initially control tools difficult to manipulate. In recent years this situation has improved considerably with availability of good quality and cheaper sensors. 


\section{Manual control vs. automatic control}

An on-line controller used during the drying can tune manually or automatically the manipulated variables:

- Manual control is the most common way to tune the manipulated variables: an operator mentally senses the overall process behaviour (usually by inference to available measurements and a strong expertise in drying operations) and adjusts the manipulated variables (e.g.: flow rate, heating power). Such control is very simple. The drawback is that this can be uneasy, due to the usual complex and multivariable behaviours occurring in drying. Moreover, the influence of disturbances (e.g.: change in feed characteristics) are usually not negligible during the drying. Also, since the frequency of this tuning is not known, new adjustments required by the new uncontrolled drying conditions may not be implemented when needed. This, therefore, leads to decrease of drying performance.

- On the other hand, automatic control refers to intelligent hard and/or soft devices that aim to tune automatically on-line the manipulated variables (e.g.: the thermostat in your house). The manipulated actions are therefore adjusted at each time, or at a fixed sampling time. Since the introduction of PID control in 1942 by Ziegler and Nichols, it has become common today to use automatic controllers in the industry. Even if implementation of automatic controllers is usually less easy than the implementation of manual control, overall performances in the process operation can be rapidly improved (e.g.: the disturbances do less affect the drying during automatic control than during manual control). Multivariable controllers can also be more easily handled than the manual ones. 
This paper focuses on automatic controller approaches, since these allow one to obtain better performance in the control of complex systems such as drying processes.

\section{Needs for a model for control}

For automatic control, a "model" is usually needed to tune the controller. Such a model is either an "experience based model" or a "numerical model":

- For an operator who tunes the manipulated variables manually, a model based on the expertise (of the operator) is developed through years of experience. It takes therefore time for the operator to learn and then, the tuning of the controllers strongly depends on the operator, who is not continuously supervising the drying. Another drawback is that this model is obviously only available if the operator is still assigned to this particular dryer!

- For the control of more complex systems, "numerical models" are developed. The easy availability of computers over past two decades makes the development of this numerical tool possible and cost-effective ${ }^{[12,13]}$. Development of such models is similar to the development of models used for process simulation in drying engineering. These fall into the following categories:

- Models based on first principles (based on heat, mass and momentum balances) leading to an explicit model described by a set of static and/or dynamic equations, ordinary and/or partial differential equations, linear and/or nonlinear equations. The 
main advantage of these models is that most of the parameters have a physical significance (e.g.: heat transfer coefficient, diffusion coefficient), which make these models the most helpful to get a better knowledge of the drying phenomena. Therefore, extrapolation of the use of these models in new drying conditions is easy. The drawback may be the time needed for the development. Moreover, it may not be possible to model any behaviours involved, leading to fitting some parameters to a "black box" model. Large computational time needed to solve complex behaviours on-line may also be a hard constraint when a model based control algorithm for online control is used.

- Knowledge-based models, where no a priori first principle knowledge is needed, but where many process data are needed to design the model such as: fuzzy model, neural network model, black box model and genetic algorithm based model. The main advantage of these models is in the relatively short time to formulate the models. The first drawback is dealing with the choice and use of the initial data set. Moreover, the validity of the model outside the data set is not known and the model parameters have less physical significance than in a first principle model. Therefore, extrapolation of the use of these models in new drying conditions is uneasy.

In this paper, the control approaches are based on "numerical" models, since we advocate that they lead to better performances for the control of complex systems, like drying processes. 


\section{Control strategies}

In control theory, no universal controller exists to solve any control problems. Therefore, a vast amount of tools are available. According to the previous remarks on the approaches treated in this paper, only the main control strategies used in drying engineering are discussed here. The most important control strategies in a general framework are as follows:

\section{Open loop control strategies}

- Model based methods:

O Optimal model- based control theory is a mathematical field that is concerned with control policies that can be deduced using optimization algorithms ${ }^{[14]}$. The control that minimizes a certain cost of operation is called the optimal control. Model based optimal control deals with the problem of finding a control law for a given model such that a certain optimality criterion is achieved. It can be derived using Pontryagin's minimum principle. Model based optimization techniques lead to the real theoretical optimal tuning of the manipulated variables. In drying this is clearly the best approach when the desired product specifications, the uncontrolled operating conditions and the feed characteristics are accurately known in advance. Unfortunately, if the reality makes things too different (which is the case most of the time), closed loop optimization approaches are better strategies. 
- Data based methods:

- There has been widespread interest from the control community in applying the genetic algorithm (GA) to problems in control systems engineering ${ }^{[15]}$. The GA is a particular class of evolutionary algorithms that use techniques inspired by evolutionary biology such as inheritance, mutation, natural selection and crossover. Compared to traditional search and optimization procedures, such as calculus-based and enumerative strategies, the GA is robust, global and generally more straightforward to apply in situations where there is little or no a priori knowledge about the process to be controlled. As the GA does not require derivative information or a formal initial estimate of the solution region and because of the stochastic nature of the search mechanism, it is capable of searching the entire solution space with more likelihood of finding the global optimum. The drawback is still today the computation time, which can extend to several days.

\section{Closed loop control strategies}

- Model based methods:

○ PID control was created in 1942. It is a simple and powerful tool, especially since it allows obtaining decent regulation results with small investments. Even today, PID represents $90 \%$ of the control tools used in the industry ${ }^{[16]}$. PID control stands for Proportional, Derivative and Integral. The PID controller is usually used to solve a regulation problem, i.e. when a process 
dynamic characteristic (the controlled variable considered) has to track as best as possible a set-point. Each of these three actions (P, I and D) gives a particular benefit to the closed-loop control structure and are all based on the error, which is the difference between the desired set-point and the real value of the controlled variable. To some extent, the proportional control accounts for the actual error, the integral control accounts for the past error, the derivative control accounts for the future error. Comparing the effects of each of these controllers on the closed-loop system with respect to the open-loop system leads to the performance analysis given in table 1 .

o Optimal model- based control theory is concerned with control policies that can be deduced using optimization algorithms ${ }^{[17]}$. The control that minimizes a certain operating cost is called the optimal control. Optimal control deals with the problem of finding a control law for a given system such that a certain optimality criterion is achieved. Both off-line and on-line optimization procedures may be combined to decrease the on-line computational time. The optimal control problem may be stated as a state linear quadratic regulator (LQR): it is no more than a state feedback matrix gain where the matrix gain is a solution of the continuous time dynamic Riccati equation induced by the model. Its main drawback is that it requires at each time instant a measure of the state of the process, which is often not completely known.

- Model-based predictive control, also named model predictive control, or receding horizon control is a particular class of optimal controller ${ }^{[18]}$. It consists in solving an explicit optimization problem formulated into the future. The main advantage is that constraints (such that manipulated variables physical limitations, constraints due to safety ...) can be explicitly 
specified into this formulation. In this structure, a model aims to predict the future behaviour of the process and the best behaviour is chosen by a correct tuning of the manipulated variables. This procedure is repeated at each sampling time with the update on the process measurements. Since its first development at the early 70's, many concepts have appeared (DMC, QDMC, GPC ...) and it has become the second control paradigm in the history of control. Thousands of industrial applications of MPC exist today, for example in the chemical and petrochemical industries.

○ Robust control provides tools for systematically accounting for a priori known model uncertainties into the controller design ${ }^{[19]}$. These tools let to identify worst-case scenarios and automatically generate controllers with reduced sensitivity to such parameter variations and modelling errors.

○ Underlining the design of robust controllers is the so called "internal model control" (IMC) principle ${ }^{[20]}$. It states that unless the control strategy contains, either explicitly or implicitly, a description of the controlled process (i.e., a model), then either the performance or the stability criterion, or both, will not be achieved. The corresponding IMC design procedure encapsulates this philosophy and provides robust properties. The primary role of this structure is to attenuate uncertainties in the feedback using the difference between process and model controlled variables. The strategy and the concept that it embraces are clearly very powerful. Indeed, the IMC principle is the essence of model based control and all model based controllers can be designed within its framework. 
o Observer-based control is a very powerful tool developed in nonlinear control theory ${ }^{[21]}$. The main idea is to design a model-based soft-sensor (the observer). It aims at estimating on-line some key dynamic variables (e.g.: a humidity profile inside the product) or an unknown model parameter (e.g.: a heat transfer coefficient) according to available measurements, the value of the manipulated variables and the model. The limitation of the feasibility of such approach depends on both the mathematical structure of the model and the sensitivity of the estimated variables with respect to available measurements. The observer-based controller is very helpful for the state estimation needed in some control strategy, like state feedback control or LQR (which is an optimal state feedback controller).

- Data based methods:

o The basic idea behind expert system is simply that expertise, which is the vast body of task-specific knowledge, is transferred from a human to a computer ${ }^{[22]}$. This knowledge is then stored in the computer which is used for specific advice. The computer can make inferences from on-line measures and draw a specific conclusion. Then like a human consultant, it gives advices for the tuning of the manipulated variables and explains, if necessary, the logic behind this advice. It provides powerful and flexible means for obtaining solutions to a variety of problems that often cannot be dealt with by other, more traditional methods. 
○ The fuzzy logic control method ${ }^{[23]}$ is based on a large number of process data. They are processed according to human based fuzzy "If-Then" rules, which can be expressed in plain language words, in combination with traditional non-fuzzy processing. Then, the resulting outputs from all the individual rules are averaged into one single defuzzified signal which tells the controller what to do. Fuzzy logic is used in system control and analysis design, because it shortens the time for engineering development and sometimes, in the case of highly complex systems, is the only way to solve the problem. Fuzzy logic controllers may be combined with expert systems.

\section{Feed-forward control and feed-back control}

In automatic control, two control schemes can be combined for control purpose:

- A feed-back control structure, which employs a sensor to measure the drying characteristics we want to control (e.g.: the mean moisture content at the outlet). It also requires the desired behaviour for this characteristic during the drying (e.g.: a mean moisture content set-point). After comparison of these two values, the controller aims to tune the manipulated variables (e.g.: the infrared irradiation) according to the chosen controller. This structure is the key element of automatic control.

- A feed-forward control structure, which also employs a sensor to measure a drying characteristic, named input disturbance (e.g.: the mean moisture content in feedstock). The idea is to account for this disturbance in the tuning 
of the manipulated variables before it does affect the controlled variables considered. This requires additional sensors, knowledge of the effect of the disturbances over the manipulated variables and controlled variables, which increases the initial engineering costs. In the meantime, such investments may lead to improved dryer operation. Since many input disturbances are present during the drying, many feed-forward control structures have been developed in drying engineering.

\section{USE OF CONTROL TOOLS IN DRYING}

In this part, an analysis of 71 publications dealing with both drying and control is presented. It also underlines some recent trends in control approaches and control tools applied in drying technologies.

First, one can see in figure 1 that the interest of papers dealing with control in drying engineering has increased: (see tables 2, 3 and 4), $61 \%$ of them were published in the last 8 years (from 1998 to the first half of 2005) whereas fewer papers where published in the previous 19 years (between 1979 and 1997). Consequently, the yearly mean publication rate of papers dealing with control aspects in drying has been multiplied by 3.7 since 1998 . Clearly, since a few years, control approach seems finally to emerge successfully in drying industry, which happens a few decades ago in other large chemical engineering units such as those in the petrochemical industry.

Concerning journals and conferences where these works were published, figure 2 and table 5 clearly underlines that Drying Technology is the major journal of choice for dissemination of 
works on control of dryers: it covers $33 \%$ of the published papers dealing with both control and drying. It is not a surprise since it is the most important journal dealing with drying science and technology. Another relevant journal is the Journal of Agricultural Economic Research, where $14 \%$ of the papers were published. Concerning conferences, the bi-annual International Drying Symposium (IDS) is also of great interest, especially since 2000 in terms of publications combining control and drying aspects. On the other side, few works are published in major control journals, such as Automatica. Yet, it is interesting to note that the only one paper published in Automatica is also one of the oldest available in this review ${ }^{[59]}$ : for the sugar industry, it compares performances of the uncontrolled rotary dryer with two closed-loop controllers (an optimally tuned PID and a state feedback based on a state observer). This analysis underlines the fact that effort has to be made on both sides between drying and control communities to have more common studies.

Concerning the application domains of control tools in drying, $66.1 \%$ of the applications deal with food (see table 6). This is not a surprise, since food has a direct impact on daily life: food drying controls quality of the dried product. That is also why the first publication in food drying control is one of the oldest listed in this review (1983). There are also at least eight times more applications in food than in any other domain! Since 1992, emerging applications have appeared with few papers in painting, pharmaceuticals, paper and wood applications. This also clearly underlines the real emergence of control in drying today.

Regarding control objectives, a trend has clearly appeared since 1998 (see table 7). On one hand, regulation issues are still studied in drying; besides the yearly mean publication rate has been multiplied by 3 since 1998. On the other side, the yearly mean publication rate of papers dealing with both optimal control and drying has been multiplied by 10 since 1998 ! 
This clearly underlines the recent needs to really optimize the dryer efficiency, which is today possible with still more efficient computer- based optimization control tools.

Various tools from control engineering are used for drying and may also be combined together. First, table 8 shows that the use of closed-loop optimizers (MPC, LQR ...) has emerged for both regulation and optimal control. Finally, advanced closed-loop control algorithms like MPC, successfully used in the chemical industry since 30 years, are now also used in drying. Like most of the industries, the 60 year old PID is still the main control tool used in drying to solve regulation issues. Due to easy implementation, tuning procedure well-know by technicians, as well as ability to lead to good performances, the PID control is indeed well suitable for regulation. A comparison of the numbers of papers based on closedloop optimizers and PID shows that optimization of the drying conditions has recently become more important than regulation: indeed, optimization often allows obtaining really interesting improvements, both in terms of final product quality and decrease in cost and energy consumption. Open-loop optimizers are also helpful for some cases in regulation, but are more combined with closed-loop optimizers: e.g., in order to reduce the on-line computation time required by the closed-loop optimizers by solving off-line the optimal behaviour of the drying. There is something particular in drying, which is not true for many other industries. Indeed, many disturbances may be present during the drying, e.g. the change in the moisture content of the product at the dryer inlet. A very important control issue is to handle them as best as possible, since the impact of this kind of disturbances over the final product quality is usually very strong in drying. A major effort has therefore been put to use feed-forward control, which is the basic structure to handle such disturbances. This is not the case in all other industries, since such impact may not be so strong there and since such structure may lead to a small improvement over the final results. Yet, in terms of 
control, such an approach is very helpful in drying, since it allows accounting for such disturbances before their impact has started. Strangely, in the meantime, such feed-forward structure is not yet employed for optimal control, whose performances could therefore clearly be improved. Concerning Internal Model Control, it is a simple and powerful control structure that has the ability to correct errors due to modelling errors and uncertainty. This control structure is used in drying for both regulation and optimal control. Fuzzy controller, usually based on data analysis, is also used for regulation purpose but is not suitable for optimal control in drying. Observer is also an interesting tool, since it can be seen as a software sensor which aims at estimating unmeasured variables and unknown model parameters. More studies will certainly use this idea in the future since it allows, combined with full state control approaches like LQR, to get a very tight control.

Nowadays, a control algorithm is usually based on a model, which helps to represent the process behaviours inside the control strategy. As previously underlined, this model can have various representations. In drying, black-box models are classically used since they are quiet easy to obtain, basic and simple to use in a control strategy. Since 1998, even if they are still usually more complex to obtain, first principle models are more used since they are more accurate to represent complex behaviours involved in drying: the yearly mean publication rate of such studies has been multiplied by 11 since 1998 (see table 9)! This modelling approach is really helpful, especially in optimal control strategies. Recent joined development of optimal control and first principle model is therefore not a surprise, especially since 1998 .

Since a model is very helpful for control synthesis, the modelling aspect is therefore the first question to tackle in a control study. Table 10 shows that simple and easy to obtain black- 
box models are more often use for regulation purpose than complex but more accurate first principle models. But, if one needs to get optimal drying conditions, an optimal controller usually based on a first principle model is preferred. Therefore, stronger production needs specified through the control objective requires the development of more accurate models.

\section{SUMMARY}

The idea of this paper was first to remind some basic principles of standard control tools and then to show how they are now used in drying technology. Indeed, even if drying is a very old technology, the emergence of control applications in drying is recent: the first real application of control theory in drying was published in 1979 and the yearly mean publication rate of such papers has increased by 3.7 of since 1998. In this paper, some motivations have been given to demonstrate the benefits of the industrial implementations of such control tools. It allows to get a better control of the dryers and to improve the drying yield: drying time, external energy consumption needed during the drying, off-specification production and drying cost may be decreased. In terms of application domain of control, drying of food is from far still the most important (66\% of the papers). This is not a surprise, since food has a direct daily impact on the human beings life and that food control quality is therefore very important. Nevertheless, new application domains are emerging since 1992 in painting, pharmaceuticals, paper and wood applications. Regarding control itself, it is interesting to notice that since 1998, more attention have been put in the development of optimal control strategies (the yearly mean publication rate has been multiplied by 10 since 1998) rather than the classical regulators (the yearly mean publication rate has been multiplied "only" by 3 since 1998). This is not a surprise since, in terms of yield's improvement, optimal strategies based on closed loop optimizers, open loop optimizers or 
both of them, do better than regulators classically based on PID. In the meantime, the use of such optimal controllers requires the development of more accurate models: the yearly mean publication rate of papers using a black-box model for control in drying has been multiplied by 2 since 1998, whereas the yearly mean publication rate of papers using a first principle model has been multiplied by 11 since 1998. This increase is quiet similar to the increase of the papers based on optimal control strategies. However, it is uneasy to say if the development of optimal strategies led to search for a better knowledge of the drying behaviours, or if the development of such first principle model kicked off the use of optimal strategies in drying. It is more certainly due to a stimulating parallel growth. It is sure that the future applications of optimal control in drying will require new and more accurate first principle models, especially for applications outside food drying. Also, a more intensive use of control tools, known to be helpful to feed more process knowledge inside the control loop, is also awaited in the future: observers (model based soft sensors), state feedback controllers and non-linear controllers. Finally, as we have seen, with 60000 products dried and 100 dryer types commonly used worldwide ${ }^{[1]}$, a real potential of control applications in drying exists. With collaboration between the control and drying communities, it is expected that the industrial drying operation will continue to improve its energy efficiency while enhancing product quality and reducing the negative environmental impact of dryers. Advances in control area could thus be applied to decrease the cost of the drying systems. 


\section{REFERENCES}

1. Mujumdar, A.S. 2004. Guide to Industrial Drying, Principles, Equipment and New Developments, In International Workshop and Symposium on Industrial Drying. Mumbai, India.

2. Kudra, T. 2004. Energy Aspects in Drying. Drying Technology 22(5):917-932.

3. Bhatia, M. 2004. Revolutionary Concept in Product Drying using Desiccant Dehumidification. In International Workshop and Symposium on Industrial Drying, paper SY174. Mumbai, India.

4. Perera, C.O. 2005. Selected Quality Attributes of Dried Foods. Drying Technology 23:717-730.

5. Ryniecki, A., Nellist, M.E. 1991a. Optimization of Control Systems for Near-Ambient Grain Drying:Part 2, The Optimization Procedure. Journal of Agricultural Engineering Research 48:1-17.

6. Ryniecki, A., Nellist, M.E. 1991b. Optimization of Control Systems for Near-Ambient Grain Drying: Part 2, The Optimizing Simulations. Journal of Agricultural Engineering Research 48:19-35.

7. Mc Farlane, N.J.B and Bruce, D.M. 1996. A Cost Function for Continuous-flow Grain Drying and its Use in Control. Journal of Agricultural Engineering Research 65:63-75.

8. CADDET 1997. Advanced Control Techniques Improve Drying Energy Performance. CADDET newsletter 4.

9. CADDET 2000a. Energy Saving using Model-Based Predictive Control. CADDET Technical Brochures http://www.caddet.org/infostore/display.php?id=3946.

10. CADDET 2000b. Model-based Predictive Control System Saves Energy. CADDET Technical Brochures R371.

11. Iguaz, A., Budman, H. and Douglas, P.L. 2002. Modelling and Control of an Alfalfa Rotary Dryer. Drying Technology 20(9):1869-1887.

12. Menshutina, N.V. and Kudra, T. 2000. Computer Aided Drying Technologies. In International Drying Symposium, paper 414. The Nederlands.

13. Menshutina, N.V. and Kudra, T. 2001. Computer Aided Drying Technologies. Drying Technology 19(8):1825-1849.

14. Kirk, D. 1970. Optimal Control Theory: an Introduction. Prentice-Hall.

15. Fogel, D.B. 1994. An Introduction to Simulated Evolutionary Optimization. IEEE Transactions on Neural Networks 5:3-14. 
16. Aström, K.J., Hägglund, T., Hang, C.C. and Ho, W.K. 1993. Automatic Tuning and Adaptation for PID Controllers - Survey. Control Engineering Practice 1(4):699-714.

17. Biegler, L.T. and Grossman, I.E. 2004. Retrospective on Optimization. Computers and Chemical Engineering 28(8):1169-1192.

18. Qin, S.J. and Badgwell, T.A. 2003. A Survey of Industrial Model Predictive Control Technology. Control Engineering Practice 11(7):733-764.

19. Kwakernaak, H. 1993. Robust Control and Hळo Optimization-Tutorial Paper. Automatica 29(2):255-273.

20. Morari, M. and Zafiriou, E. 1989. Robust Process Control. Prentice-Hall, Englewood Cliffs.

21. Gauthier, J.P., Hammouri, H. and Othman, S. 1992. A Simple Observer for Nonlinear Systems Applications to Bioreactors. IEEE Transactions on Automatic Control 37 (6):875-880.

22. Liao, S-H. 2005. Expert System Methodologies and Applications-A decade Review from 1995 to 2004. Expert Systems with Applications 28:93-103.

23. Sugeno, M. 1985. Introductory Survey of Fuzzy Control. Information Sciences 36(12):59-83.

24. Abdel-Jabbar, N.M., Jumah, R.Y. and Al-Haj Ali, M.Q. 2002. Multivariable Process Identification and Control of Continuous Fluidized Bed Dryers. Drying Technology 20(7):1347-1377.

25. Abdel-Jabbar, N.M., Jumah, R.Y. and Al-Haj Ali, M.Q. 2005. State Estimation and State Feedback Control for Continuous Fluidized Bed Dryers. Journal of Food Engineering 70(2):197-203.

26. Abukhalifeh, H., Dhib, R. and Fayed, M.E. 2005. Model Predictive Control of an Infrared-Convective Dryer, Drying Technology 23(3):467-511.

27. Arjona, R., Ollero, P. and Vidal, B. F. 2005. Automation of an Olive Waste Industrial Rotary Dryer. Journal of Food Engineering 68(2):239-247.

28. Banga, J.R. and Singh, R.P. 1994. Optimization of Air Drying of Foods. Journal of Food Engineering 23(2):189-211.

29. Bremmer, H. and Postlethwaite, B. 1994. The Development of a Relational Fuzzy Model based Controller for an Industrial Process. In IEEE Conferenc. on Fuzzy Systems, 1(6):39-44. USA.

30. Bruce, D.M. and McFarlane, N. J. B. 1993. Control of Mixed-flow Grain Dryers: An Improved Feedback-plus-Feedforward Algorithm. Journal of Agricultural Engineering Research 56(3):225-238. 
31. CADDET 2001. Benefits of Advanced Controls for Industrial Drying Processes.

CADDET Technical Brochures

http://www.caddet.org/infostore/display.php?section=1\&id=4178.

32. Carlsson, P. and Tinnsten, M. 2002. Optimization of Drying Schedules Adapted for a Mixture of Boards with Distribution of sapwood and Heartwood. Drying Technology 20(2):403-418.

33. Corrêa, N.A., Corrêa, R.G. and Freire, J.T. 2000. Adaptive Control for Drying of Paste in Spouted Bed using the GPC Algorithm. In International Drying Symposium, paper 80. The Nederlands.

34. Corrêa, N.A., Corrêa, R.G. and Freire, J.T. 2002. Self-tuning Control of Egg Drying in Spouted Bed using the GPC Algorithm. Drying Technology 20(4\&5):813-828.

35. Corrêa, N.A., Freire, F.B., Corrêa, R.G. and Freire, J.T. 2004. Industrial Trials of Paste Drying in Spouted Beds Under QDMC. Drying Technology 22(5):1087-1105.

36. Costa, C.E.S., Freire, F.B., Corre, N.A., Freire, J.T., Correa, R.G. 2005. Two-Layer Real Time Optimization of the Drying of Pastes in a Spouted Bed: Experimental Implementation. In IFAC World Congress, paper 02800. Prague, Tcheck Republic.

37. Courtois, F., Nouafo, J.L. and Trystram, G. 1995. Control Strategies for Corn Mixedflow Dryers. Drying Technology 13(5\&7):1153-1165.

38. Didriksen, H. 2000. Model based Predictive Control of a Rotary Dryer. In International Drying Symposium, paper 193. The Nederlands.

39. Dufour, P., Blanc, D., Touré, Y. and Laurent, P. 2002. Model Predictive Control for an Infrared Drying Process of a Water Based Epoxy Amine Painting. In International Drying Symposium, vol. B:1147-1154. Beijing, PRC.

40. Dufour, P., Touré, Y., Blanc, D. and Laurent, P. 2003. On Nonlinear Distributed Parameter Model Predictive Control Strategy: On-line Calculation Time Reduction and Application to an Experimental Drying Process. Computers and Chemical Engineering 27(11):1533-1542.

41. Dufour, P., Blanc, D., Touré, Y. and Laurent, P. 2004. Infrared Drying Process of an Experimental Water Painting: Model Predictive Control. Drying Technology 22(12):269-284.

42. Dufour, P., Laurent, P. and Xu, C.Z. 2004. Model Predictive Control of the Water Based Painting Drying using a Humidity Profile Soft Sensor and a Temperature Measurement. In International Drying Symposium, vol. B:911-918. Sao Paulo, Brazil.

43. Dufour, P., Laurent, P. and Xu, C.Z. 2004. Observer based Model Predictive Control of the Water Based Painting Drying using a Humidity Profile Soft Sensor and a Temperature Measurement.In International Workshop and Symposium on Industrial Drying, paper SY152. Mumbai, India. 
44. Forbes, J.F., Jacobson, B.A., Rhodes, E. and Sullivan, G.R. 1984. Model based Control Strategies for Commercial Grain Drying Systems. Canadian Journal of Chemical Engineering 62:773-779.

45. Haley, T.A. and Mulvaney, S.J. 2000. On-line System Identification and Control Design of an Extrusion Cooking Process: Part II. Model Predictive and Inferential Control Design. Food Control 11(2):121-129.

46. Huang, C.H. and Chen, T.T. 2004. An Optimal Control Problem for Controlling the Cell Volume in Dehydration and Rehydration Process. International Journal of Heat and Mass Transfer 47(17\&18):3607-3616.

47. Jaaksoo, U.J., Talvis, E.M. and Ummer, J.M. 1982. Microprocessor-Based Grain Dryer Control. In Software for Computer Control, 473-477. Madrid, Spain.

48. Kamiski, W. and Strumz, C. 1992. Optimal Control of Bioproduct Drying with respect to Product Quality. Chemical Engineering and Processing 31(2):125-129.

49. C. T. Kiranoudis, C.T., Bafas, G.V., Maroulis, Z.B. and Marinos-Kouris, D. 1995. MIMO Control of Conveyor-Belt Drying Chambers. Drying Technology 13(1\&2):7397.

50. Kokko T., Lautala P., Huhtelin, T. 2002. Advanced Control Strategy for Impingement Drying. In International Drying Symposium, vol. C:1734-1746. Beijing, PRC.

51. Kokko T., Lautala P., Huhtelin, T. 2003. Advanced Control Strategy for Impingement Drying. Drying Technology 21(10):1969-1990.

52. Krokida, M.K. and Kiranoudis, C.T. 2000. Product Quality Multi-Objective Optimization of Fluidized Bed Dryers. Drying Technology 18(1\&2):143-163.

53. Liapis, I.A., Bruttini, R. and Sadikoglu, H. 2000. Optimal Control of the Primary and Secondary Drying Stages of the Freeze Drying of Pharmaceuticals in Vials. In International Drying Symposium, paper 115. The Nederlands.

54. Liapis, I.A. and Litchfield, R.J. 1979. Optimal Control of a Freeze Dryer-I Theoretical Development and Quasi Steady State Analysis. Chemical Engineering Science 34(7):975-981.

55. Liu, Q. and Bakker-Arkema, F.W. 2001. Automatic Control of Crossflow Grain Dryers, Part 2: Design of a Model-Predictive Controller. Journal of Agricultural Engineering Research 80(2):173-181.

56. Liu, Q. and Bakker-Arkema, F.W. 2001. Automatic Control of Crossflow Grain Dryers, Part 3: Field Testing of a Model-Predictive Controller. Journal of Agricultural Engineering Research 80(3):245-250.

57. Liu, Q. and Bakker-Arkema, F.W. 2001. A Model-Predictive Controller for Grain Drying. Journal of Food Engineering 49(4):321-326. 
58. Liu, H., Zhang, J., Tang, X. and Lu, Y. 2003. Fuzzy Control of Mixed-Flow Grain Dryer. Drying Technology 21(5):807-819

59. Mann, W. 1983. Digital Control of a Rotary Dryer in the Sugar Industry. Automatica 19(2):131-148.

60. McFarlane, N.J.B. and Bruce, D.M. 1991. Control of Mixed-flow Grain-driers: Development of a Feedback-plus-feedforward Algorithm. Journal of Agricultural Engineering Research 49:243-258.

61. Murphy, T.F., Yurkovich, S. and Chen, S.-C. 1996. Intelligent Control for Paper Machine Moisture Content. In IEEE Conference on Control Applications, 826-833. Dearborn, MI.

62. Musch, H. E., Barton, G. W., Langrish, T. A. G. and Brooke, A. S. 1998. Nonlinear Model Predictive Control of Timber Drying. Computers and Chemical Engineering 22(3):415-425.

63. Nelson, D. and Gardner, T. 1996. Optimizing Paper Machine Dryer Control-A Case Study. Pulp and Paper Canada 97(11):401-407.

64. Nishizawa, J., Numata, M., Ohshima, M., Fujiwara, T. and Hashimoto, I. 1994. Temperature Profile Control of a Rotary Dryer with Multivariable Model Predictive Control. Control Engineering Practice 2(6):159-162.

65. Nybrant, T.G. 1988. Modelling and Adaptive Control of Continuous Grain Driers. Journal of Agricultural Engineering Research 40(3):165-173.

66. Olmos, A., Trelea, I.C., Courtois, F., Bonazzi, C. and Trystram, G. 2002. Dynamic Optimal Control of Batch Rice Drying Process. Drying Technology 20(7):1319-1345.

67. Panda, R.C. and Ramachandra Rao, V.S. 2004. Model based Control of a Continuous Fluidized Bed Dryer. In IEEE Conference, paper WE-1-1. Glasgow.

68. Pérez-Correa, J. R., Cubillos, F., Zavala, E., Shene, C. and Álvarez, P.I. 1998. Dynamic Simulation and Control of Direct Rotary Dryers. Food Control 9(4):195-203.

69. Platt, D., Palazoglu, A. and Rumsey, T.R. 1992. Dynamics and Control of Cross-Flow Grain Dryers. II. A Feedforward-Feedback Control Strategy. Drying Technology 10(2):333-363.

70. Ravi V., Sundaramoorthy, S. and Ramachandra Rao, V.S. 1986. Computer Control of a Fluidized Bed Dryer with Varying Temperature Condition. In International Drying Symposium, 1:232-237. Cambridge, USA.

71. Sadikoglu, H., Ozdemir, M. and Seker, M. 2003. Optimal Control of the Primary Drying Stage of Freeze Drying of Solutions in Vials Using Variational Calculus. Drying Technology 21(7):1307-1331. 
72. Sadikoglu, H., Liapis, A.I and Cross, O.K. 1998. Optimal Control of the Primary and Secondary Drying Stages of Bulk Solution Freeze Drying in Trays. Drying Technology 16(3-5):399-431.

73. Sieniutycz, S. and Szwast, Z. 1984. Optimization of Multistage Crosscurrent Fluidized Drying by a Special Algorithm of the Discrete Maximum Principle. Chemical Engineering Journal 25:63-75.

74. Siettos, C.I., Kiranoudis, C.T. and Bafas, G.V. 1999. Advanced Control Strategies for Fluidized Bed Dryers. Drying Technology 17(10):2271-2291.

75. Tarasiewicz, S., Ding, F., Kudra, T. and Mrozek, Z. 2000. Fast and Slow Generation of a Multilevel Control for the Wood Drying Process. Drying Technology 18(8):17091735 .

76. Tarasiewicz, S., Ding, F. and Léger, F. 1998. Modeling Simulation and Control of the Wood Drying Process. Part 2. Variable Control Structure. Drying Technology 16(6):1085-1100.

77. Temple, S. J. and Van Boxtel, A. J. B. 2000. Control of Fluid Bed Tea Dryers:Controller Design and Tuning. Computers and Electronics in Agriculture 26(2):159-170.

78. Temple, S. J., Van Boxtel, A. J. B. and Van Straten, G. 2000. Control of Fluid Bed Tea Dryers: Controller Performance under Varying Operating Conditions Computers and Electronics in Agriculture. Computers and Electronics in Agriculture 29(3):217231.

79. Thibault, J. and Duchesne, C. 2004. Evaluation of Simple Control Strategies for Rotary Dryers. Drying Technology 22(5):947-962.

80. Thyagarajan, T., Shanmugam, J., Ponnavaikko and Panda, R.C. 2000. Hybrid Intelligent Control Scheme for Air Heating System Using Fuzzy Logic and Genetic Algorithm. Drying Technology 18(1\&2):165-184.

81. Trelea, I.C., Trystram, G. and Courtois, F. 1997. Optimal Constrained Non-linear Control of Batch Processes: Application to Corn Drying. Journal of Food Engineering 31(4):403-421.

82. Trelea, I.C., Trystram, G. and Courtois, F. 1999. Influence of Model Uncertainty on the Dynamic Optimal Control Performance of a Batch Corn Drying Process. Drying Technology 17(6):1173-1180.

83. Sanjabi, F., Dhib, R. and Cuenca, M.A. 2004. Computer Simulation and Optimal Control of Continuous Infrared Dryers, In International Workshop and Symposium on Industrial Drying. Mumbai, India.

84. Valdovinos, B., Salgado, M.A.,. García, M.A., Morales, C. and Rodríguez, G.C. 2000. Fuzzy Logic Control for a Drum Dryer of Foodstuff. In International Drying Symposium, paper 61. The Nederlands. 
85. Vasconcelos, L.G.S. and R. Maciel Filho, R. 1998. Development of a Supervisory Control Strategy for the Optimal Operation of Grain Dryers. Drying Technology 16(9\&10):2017-2031.

86. Whitfield, R.D. 1988. Control of a Mixed-flow Drier Part 1: Design of the Control Algorithm. Journal of Agricultural Engineering Research 41(4):275-287.

87. Whitfield, R.D. 1988. Control of a Mixed-flow Drier Part 1: Test of the Control Algorithm. Journal of Agricultural Engineering Research 41(4):289-299.

88. Yliniemi, L. 1999. Advanced Control of Rotary Dryer. PhD Thesis, University of Oulu, Finland.

89. Zaror, C. A. and Pérez-Correa, J. R. 1991. Model based Control of Centrifugal Atomizer Spray Drying. Food Control 2(3):170-175.

90. Zhang, Q. and Litchfield, J.B. 1994. Knowledge Representation in a Grain Drier Fuzzy Logic Controller. Journal of Agricultural Engineering Research 57(4):269-278. 


\section{LIST OF FIGURES}

Figure 1: Number of publications dealing with control in drying versus the year of publications.

Figure 2: Journals, conferences and Ph.D. theses where works dealing with control in drying are published. 


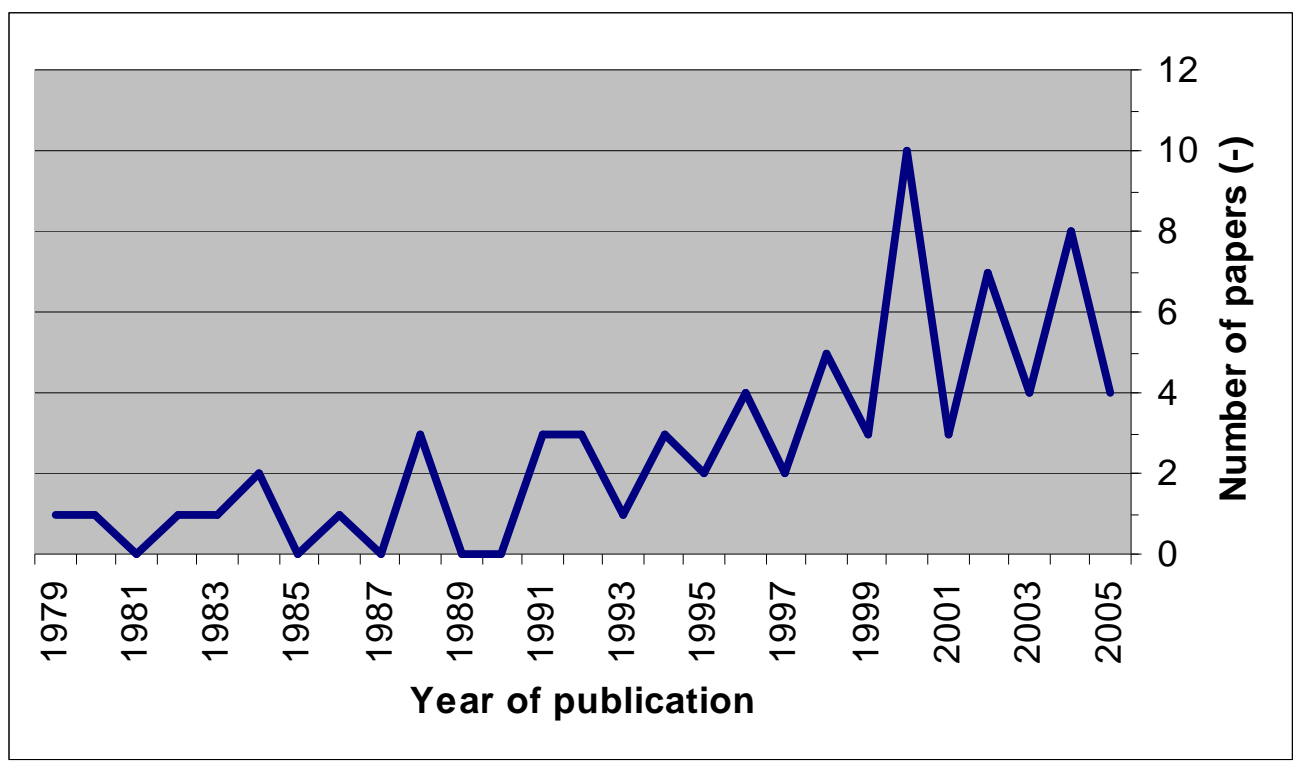

Figure 1 


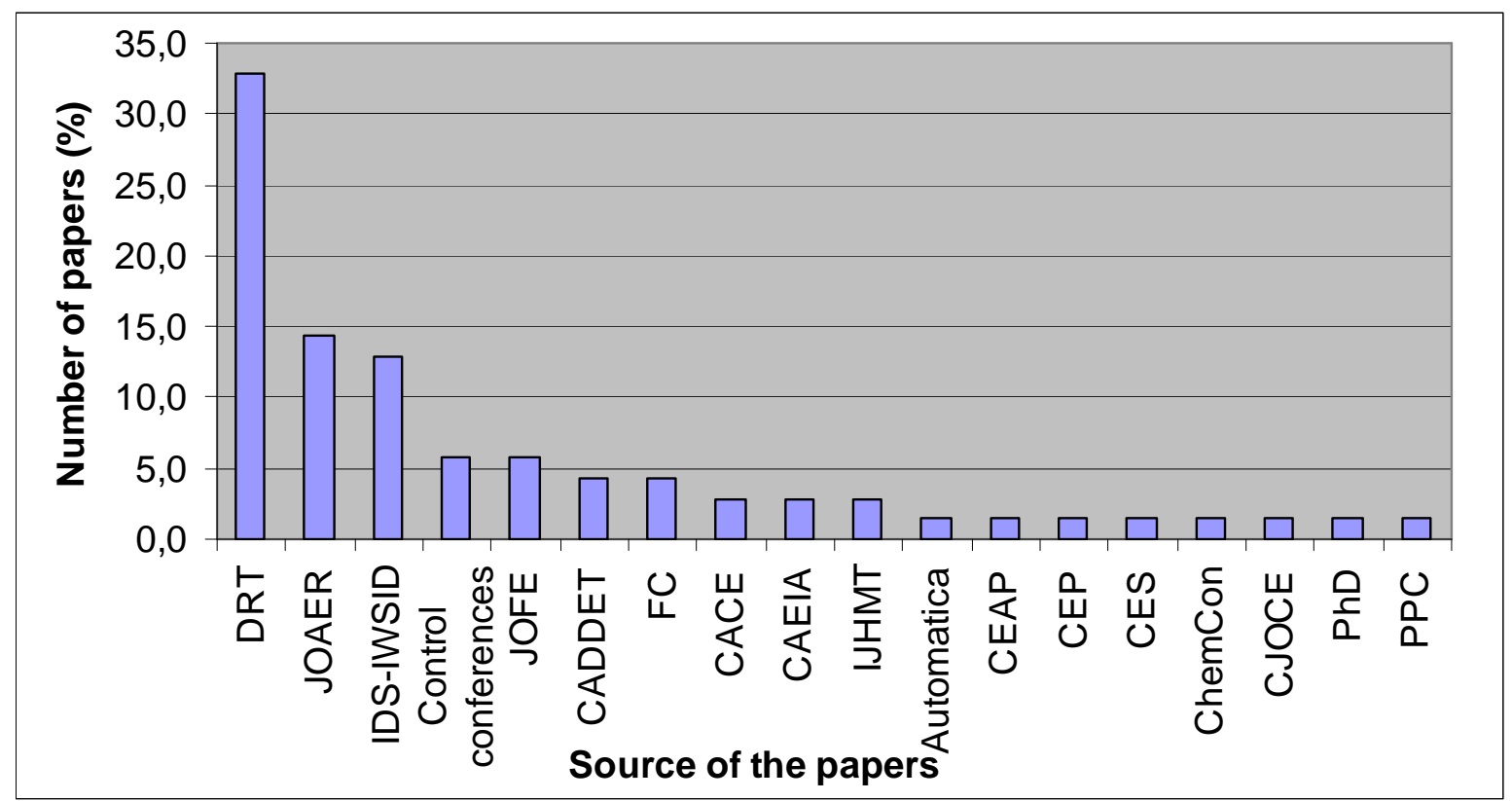

Figure 2 


\section{LIST OF TABLES}

Table 1: Improvements of the performances with closed loop control according to each actions of a PID controller.

Table 2: List of the references dealing with control aspects in drying (part 1).

Table 3: List of the references dealing with control aspects in drying (part 2).

Table 4: List of the references dealing with control aspects in drying (part 3).

Table 5: Journals and conferences acronyms given in figure 2.

Table 6: Number of papers where control tools are used in drying and year of the first publication, both versus the type of applications domains.

Table 7: Number of papers versus the type of control problems solved and versus the year of publication.

Table 8: Type of control tools used for regulation and optimal control in drying.

Table 9: Number of papers versus the type of model used in the control strategies versus the year of publication.

Table 10: Type of models used in the control tools in drying versus the control objective. 
Improvements of the performances with closed loop control according to each actions of a PID controller.

\begin{tabular}{|c|c|c|c|}
\hline Closed loop response performances & Rise time & Overshoot & Steady-state error \\
\hline Optimal desired controllers & minimum & minimum & minimum \\
\hline P controller & decrease & increase & decrease \\
\hline I controller & decrease & increase & eliminate \\
\hline D controller & small change & decrease & small change \\
\hline
\end{tabular}


List of the references dealing with control aspects in drying (part 1).

\begin{tabular}{|c|c|c|c|c|c|c|c|c|c|c|c|c|c|c|c|c|c|c|c|c|c|}
\hline \multirow{2}{*}{ 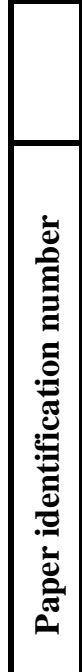 } & \multicolumn{8}{|c|}{ Application domain } & \multicolumn{2}{|c|}{$\begin{array}{c}\text { Control } \\
\text { problem } \\
\text { solved }\end{array}$} & \multicolumn{3}{|c|}{$\begin{array}{c}\text { Type of } \\
\text { model used }\end{array}$} & \multicolumn{8}{|c|}{ Type of control tools used } \\
\hline & $\begin{array}{l} \\
\\
8 \\
1\end{array}$ & 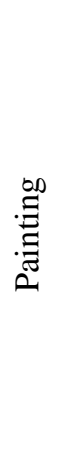 & 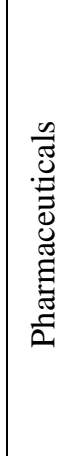 & 矛 & $\begin{array}{l}\overrightarrow{8} \\
\dot{0}\end{array}$ & $\begin{array}{l}\overline{0} \\
0 \\
\grave{0} \\
\stackrel{0}{0}\end{array}$ & 莺 & 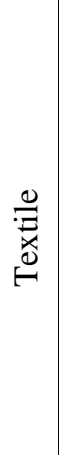 & 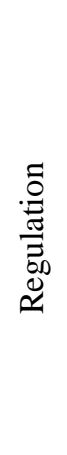 & 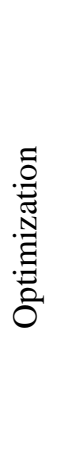 & 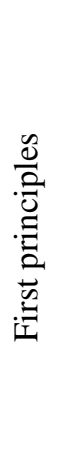 & $\begin{array}{l}\ddot{0} \\
\frac{0}{1} \\
\frac{\dot{d}}{0} \\
\frac{\pi}{n}\end{array}$ & 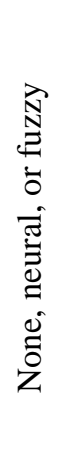 & 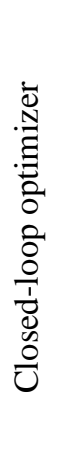 & 言 & 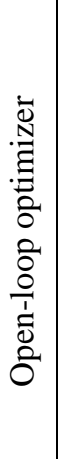 & 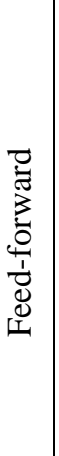 & $\sum$ & 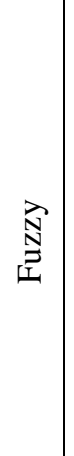 & $\begin{array}{l}\overline{0} \\
\vec{D}_{0} \\
\stackrel{0}{0}\end{array}$ & ت্் \\
\hline 24 & & & & & & & & & & 1 & & 1 & & 1 & & & & 1 & & & \\
\hline 25 & & & & & & & & & 1 & & & 1 & & & & & & & & 1 & 1 \\
\hline 26 & & & & & & & & & 1 & & & 1 & & 1 & & & & & & & \\
\hline 27 & 1 & & & & & & & & 1 & & & & 1 & & 1 & & & & & & \\
\hline 28 & 1 & & & & & & & & & 1 & 1 & & & & & 1 & & & & & \\
\hline 29 & 1 & & & & & & & & 1 & & & & 1 & & & & & 1 & 1 & & \\
\hline 30 & 1 & & & & & & & & 1 & & & 1 & & & 1 & & 1 & & & & \\
\hline 9 & 1 & & & & & & & & & 1 & & & & 1 & & & & & & & \\
\hline 31 & & & & & & & & 1 & & 1 & & & & 1 & & & & & & & \\
\hline 8 & 1 & & & & & & & & & 1 & & & & 1 & & & & & & & \\
\hline 32 & & & & & 1 & & & & & 1 & 1 & & & & & 1 & & & & & \\
\hline 33 & 1 & & & & & & & & 1 & & & 1 & & 1 & & & & & & & 1 \\
\hline 34 & 1 & & & & & & & & & 1 & & 1 & & 1 & & & & & & & \\
\hline 35 & 1 & & & & & & & & 1 & & & 1 & & 1 & & & & & & & \\
\hline 36 & 1 & & & & & & & & 1 & & & 1 & & 1 & & 1 & & & & & \\
\hline 37 & 1 & & & & & & & & 1 & & & 1 & & & 1 & & 1 & & & & 1 \\
\hline 38 & 1 & & & & & & & & 1 & & 1 & & & 1 & & & 1 & & & & \\
\hline 39 & & 1 & & & & & & & & 1 & 1 & & & 1 & & & & 1 & & & \\
\hline 40 & & 1 & & & & & & & & 1 & 1 & & & 1 & & & & 1 & & & \\
\hline 41 & & 1 & & & & & & & & 1 & 1 & & & 1 & & & & 1 & & & \\
\hline 42 & & 1 & & & & & & & & 1 & 1 & & & 1 & & & & 1 & & 1 & \\
\hline 43 & & 1 & & & & & & & & 1 & 1 & & & 1 & & & & 1 & & 1 & \\
\hline $\begin{array}{l}44 \\
45 \\
46\end{array}$ & 1 & & & & & 1 & & & $\begin{array}{l}1 \\
1\end{array}$ & 1 & 1 & $\begin{array}{l}1 \\
1\end{array}$ & & 1 & 1 & 1 & $\begin{array}{l}1 \\
1\end{array}$ & 1 & & & \\
\hline
\end{tabular}

\footnotetext{
${ }^{1}$ At least, one of the following topics present in the paper: adaptive control, artificial neural network, genetic algorithm, inferential approach, non-linear control, state feedback control, sliding mode control, Smith predictor.
} 
List of the references dealing with control aspects in drying (part 2).

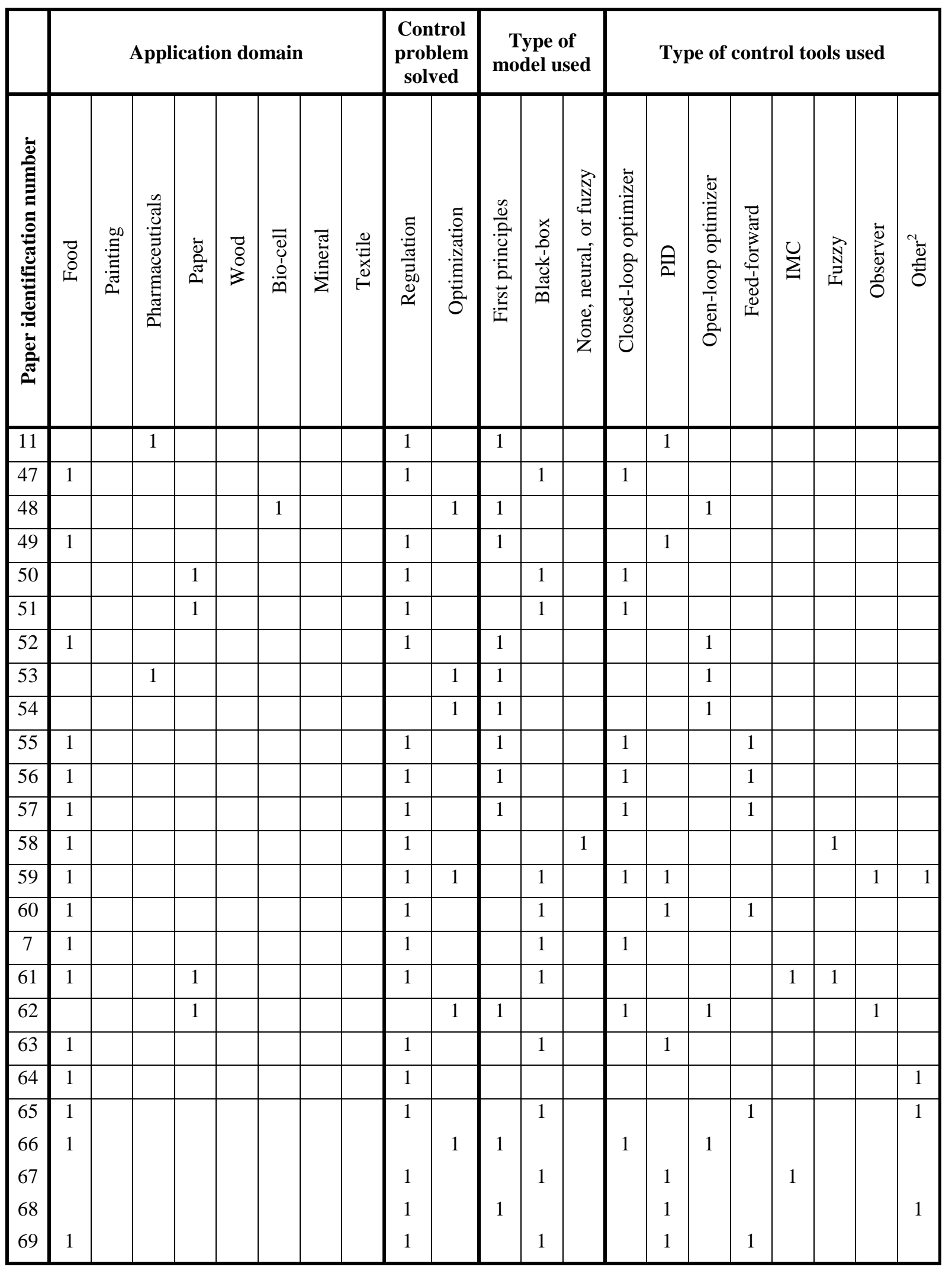

${ }^{2}$ At least, one of the following topics present in the paper: adaptive control, artificial neural network, genetic algorithm, inferential approach, non-linear control, state feedback control, sliding mode control, Smith predictor. 
List of the references dealing with control aspects in drying (part 3).

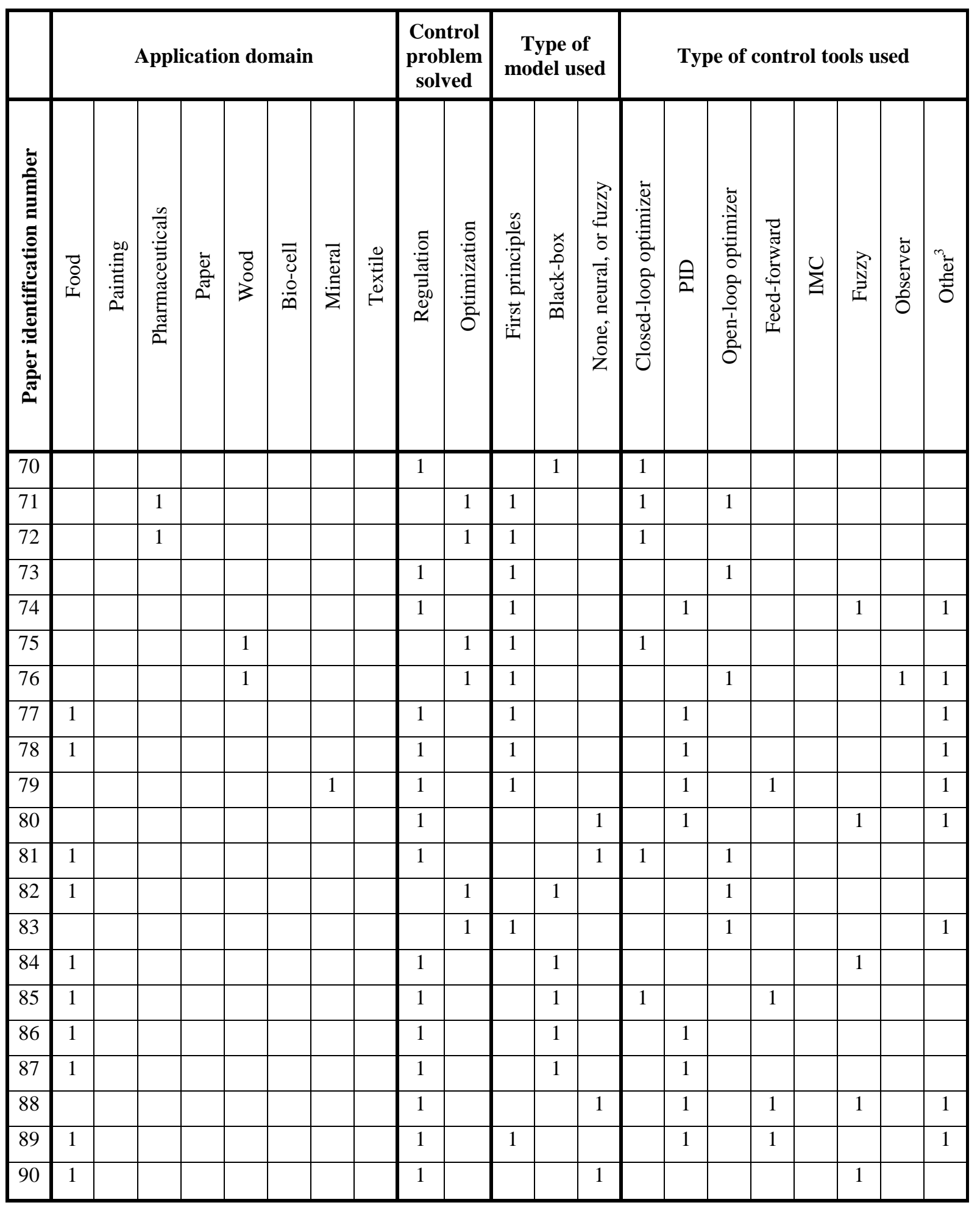

\footnotetext{
${ }^{3}$ At least, one of the following topics present in the paper: adaptive control, artificial neural network, genetic algorithm, inferential approach, non-linear control, state feedback control, sliding mode control, Smith predictor.
} 
Journals and conferences acronyms given in figure 2 .

\begin{tabular}{|c|c|}
\hline Journal or conference acronym & Journal name \\
\hline DRT & Drying Technology \\
\hline JOAER & Journal of Agricultural Economic Research \\
\hline IDS & International Drying Symposium \\
\hline IWSID & $\begin{array}{c}\text { International Workshop and Symposium on } \\
\text { Industrial Drying }\end{array}$ \\
\hline JOFE & Journal of Food Engineering \\
\hline CADDET & $\begin{array}{c}\text { Centre for Analysis and Dissemination of } \\
\text { Demonstrated Energy Technologies. } \\
\text { http://www.caddet.org/ }\end{array}$ \\
\hline FC & Food Control \\
\hline CACE & Computers \& Chemical Engineering \\
\hline CAEIA & International Journal of Heat and Mass Transfer \\
\hline IJHMT & Automatica \\
\hline Automatica & Chemical Engineering and Processing \\
\hline CEAP & Control Engineering Progress \\
\hline CEP & Chemical Engineering Science \\
\hline CES & International Conference on Chemical Control \\
Chegulations
\end{tabular}


Number of papers where control tools are used in drying and year of the first publication, both versus the type of applications domain.

\begin{tabular}{|c|c|c|}
\hline Application domain & Number of papers (percent) & $\begin{array}{c}\text { Year of the first } \\
\text { publication }\end{array}$ \\
\hline Food & $66,1 \%$ & 1983 \\
\hline Painting & $8,5 \%$ & 2002 \\
\hline Pharmaceuticals & $6,8 \%$ & 1998 \\
\hline Paper & $6,8 \%$ & 1996 \\
\hline Wood & $5,1 \%$ & 1998 \\
\hline Bio-cell & $3,4 \%$ & 1992 \\
\hline Mineral & $1,7 \%$ & 1994 \\
\hline Textile & $1,7 \%$ & 2001 \\
\hline
\end{tabular}


Number of papers versus the type of control problems solved and versus the years of publication.

\begin{tabular}{|c|c|c|}
\hline Years & Regulation & Optimal control \\
\hline $1979-1997$ & 22 & 5 \\
\hline $1998-2005$ & 25 & 20 \\
\hline
\end{tabular}


Type of control tools used for regulation and optimal control in drying.

\begin{tabular}{|c|c|c|c|}
\hline Type of control tool & Regulation & $\begin{array}{c}\text { Optimal } \\
\text { control }\end{array}$ & $\begin{array}{c}\text { Regulation + } \\
\text { optimal control }\end{array}$ \\
\hline Closed-loop optimizer & 15 & 16 & 31 \\
\hline PID & 25 & 1 & 26 \\
\hline Open-loop optimizer & 4 & 12 & 16 \\
\hline Feed-forward & 15 & 0 & 15 \\
\hline IMC & 4 & 6 & 10 \\
\hline Fuzzy & 8 & 0 & 8 \\
\hline Observer & 2 & 5 & 7 \\
\hline Other: adaptive control, inferential & 3 & 0 & 3 \\
\hline Other: state feedback & 2 & 1 & 3 \\
\hline $\begin{array}{c}\text { Other: poles placement, Smith } \\
\text { predictor }\end{array}$ & 2 & 0 & 2 \\
\hline Other: genetic algorithm & 1 & 1 & 2 \\
\hline $\begin{array}{c}\text { Other: artificial neural network, } \\
\text { non-linear control }\end{array}$ & 1 & 0 & 1 \\
\hline Other: sliding mode control & 0 & 1 & 1 \\
\hline
\end{tabular}


Number of papers versus the type of model used in the control strategies versus the years of publication.

\begin{tabular}{|c|c|c|c|}
\hline Years & None, neural, or fuzzy & Black-box & First principles \\
\hline $1979-1997$ & 3 & 19 & 6 \\
\hline $1998-2005$ & 4 & 15 & 26 \\
\hline
\end{tabular}


Type of models used in the control tools in drying versus the control objective.

\begin{tabular}{|c|c|c|c|}
\hline $\begin{array}{c}\text { Control } \\
\text { objective }\end{array}$ & $\begin{array}{c}\text { None, neural, } \\
\text { or fuzzy }\end{array}$ & Black-box & $\begin{array}{c}\text { First } \\
\text { principles }\end{array}$ \\
\hline Regulation & 7 & 28 & 14 \\
\hline Optimal control & 0 & 5 & 18 \\
\hline
\end{tabular}

